Article

\title{
Impacts of Investment Cost, Energy Prices and Carbon Tax on Promoting the Combined Cooling, Heating and Power (CCHP) System of an Amusement Park Resort in Shanghai
}

\author{
Liting Zhang ${ }^{1,2}$, Weijun Gao $\left.{ }^{1,2}{ }^{(}\right)$, Yongwen Yang ${ }^{3, *}$ and Fanyue Qian ${ }^{1,2} \mathbb{C}$ \\ 1 Innovation Institute for Sustainable Maritime Architecture Research and Technology, Qingdao University of \\ Technology, Qingdao 266033, China; zhangliting708@163.com (L.Z.); gaoweijun@me.com (W.G.); \\ qianfanyue91@163.com (F.Q.) \\ 2 Faculty of Environmental Engineering, The University of Kitakyushu, Kitakyushu 808-0135, Japan \\ 3 Energy and Environment Engineering Institute, Shanghai University of Electric Power, \\ Shanghai 200090, China \\ * Correspondence: yangyongwen@vip.163.com
}

Received: 20 July 2020; Accepted: 13 August 2020; Published: 17 August 2020

\begin{abstract}
Poor economic performance has limited the diffusion of the combined cooling, heating, and power (CCHP) system. Various factors influence the economic performance of the CCHP system. To analyze the impacts of these different factors and promote the CCHP system, this study evaluated its comprehensive performance through a multi-criteria method, using an amusement park resort in Shanghai as a research case. First, three CCHP systems with different penetration rates were presented and simulated in a transient simulation model for comparison. The economic and environmental performance of these different penetration CCHP systems were evaluated based on the dynamic payback period and carbon dioxide emissions. The impacts of investment cost, energy prices, investment subsidy and a carbon tax on the economic performance of the three systems were discussed, and a sensitivity analysis was used to compare these factors. The results show that the current subsidy can reduce the economic gap between the CCHP system and the conventional system, but it still needs to be increased by 1.71 times to achieve market competitiveness of the CCHP system with 100\% penetration under the current investment cost and energy prices. In addition, the introduction of a carbon tax could accelerate the promotion of the CCHP system. When the carbon tax reaches $25 \$ /$ ton, the CCHP system becomes the best choice of energy supply system.
\end{abstract}

Keywords: CCHP system; dynamic payback period; investment cost; energy price; carbon tax

\section{Introduction}

As a type of energy supply for distributed energy, the combined cooling, heating and power (CCHP) system has many advantages, such as energy diversity, energy supply security and environmental friendliness [1]. It recycles the low-temperature waste heat generated by the power generation process, which can give a comprehensive utilization efficiency of up to $75 \%$ [2]. The high efficiency of the CCHP system provides significant reductions in energy costs and greenhouse gas emissions $[3,4]$, and it has been widely promoted worldwide. However, despite its proven high comprehensive utilization efficiency, the development of the CCHP system is still not ideal in many countries, especially in China. Nearly half of the more than 40 CCHP system projects in China have been out of service due to economic problems [5]. Various factors have been discussed which influence its 
economic performance, such as the design and operation strategies of the CCHP system, the energy prices, the initial cost, demand loads and incentive policies [6].

Many studies have analyzed the economic performance of CCHP systems, considering the influence of different factors. The energy price is one of the key factors that influence the operation benefits, and it can determine the economic performance of the CCHP system [7]. Eduardo et al. [8] presented the influence of the operation strategy and the energy price on the benefits of trigeneration systems combined with thermal energy storage (TES). Wang et al. [1] discussed the annual capital costs, maintenance costs and energy costs of CCHP systems with different configurations compared to conventional system, to determine the optimal system in terms of best economic performance. Tichi et al. [9] analyzed the impact of current and future energy prices on the installed capacity of CCHP systems in Iran and emphasized that the policy of selling electricity to utility is a prerequisite for the successful promotion of the CCHP system. The increase of the energy prices can help improve the promotion of installing CCHP systems. Policy support is one of the most effective ways of contributing to the economic performance of the CCHP system. Nowadays, many countries have adopted policies for the promotion of CCHP systems, such as investment subsidies [10], feed-in tariffs [11], tax support [12], etc. Rentao Dong et al. [13] analyzed the impacts of different subsidies on investment in distributed natural gas projects and highlighted that the best subsidy means should be dynamic. They demonstrated that economics changed with the adjustment of energy prices and subsidies. The increase of gas prices, reduction of electricity prices and subsidies will decrease the economics of the CCHP. Zheng et al. [11] evaluated the impact of the feed-in-tariff policy on the design capacity and performance of a hospital CCHP system.

The reason for promoting the CCHP system is energy conservation and emission reduction. Therefore, in addition to economic performance, energy and environmental effects are also important evaluation criteria in the comprehensive analysis of CCHP systems [14,15]. Some literature focuses on multi-criteria evaluation [16-18]. Nami et al. [19] assessed the sustainability and feasibility of a municipal waste-fired trigeneration plant from the thermodynamic, economic and environmental perspectives. Xiaolin Chu et al. [20] used the economic benefits, environmental sustainability and energy advantages to evaluate the CCHP system under two different carbon emission regulation policies. Because the economic performance and environmental performance of a CCHP system are evaluation indicators from two different perspectives, and usually conflict with each other [21], a few studies have used carbon credits [22] or other carbon emission trading [6] method to evaluate the environmental performance of the CCHP system.

From the literature review, there are two aspects that have received less attention. Researchers have analyzed several measures to improve the economic performance of the CCHP system. However, most of them have focused on the optimization of the configuration design and operation strategy of the CCHP system under certain conditions. The reasons that the development of the CCHP system has been limited and influencing factors of the promotion of the CCHP system have not been considered. Furthermore, most papers develop the economic evaluation and environmental evaluation of the CCHP system only by the weighted method, which lacks practical application significance.

To improve its economic advantage and promote the CCHP system, this paper proposes three different systems (conventional system without CCHP, CCHP with $50 \%$ penetration and CCHP with $100 \%$ penetration) based on a research case of an amusement park resort in Shanghai. The environmental performance of the CCHP system plays an important role in the promotion of the CCHP system. Therefore, both the economic and environmental performance of the three systems were compared. According to the carbon tax scheme levied in China since 2019 [23], this study used the carbon tax to transfer the reduction benefits of the CCHP system in carbon dioxide emissions into an economic benefit, in order to comprehensively analyze the performance of the CCHP system. Finally, we compared the impacts of different factors, including investment costs, energy prices and the carbon tax, on the promotion of the CCHP system.

Consequently, the contributions of this paper can be summarized as follows. 
1. An operation simulation of CCHP systems with different penetrations based on a transient simulation model was carried out. The dynamic payback period and carbon dioxide emissions were used to evaluate the economic and environmental performance of the CCHP system.

2. The impacts of four factors-investment cost, energy prices, subsidies and the carbon tax-on the payback period of the CCHP system were analyzed to obtain the effects on promotion of the development of the CCHP system.

3. Through sensitivity analysis, the impact significance of different factors on the economy of the CCHP system was compared, and the correlation with the promotion effect of the CCHP system was analyzed.

The research flow of this study is shown in Figure 1.

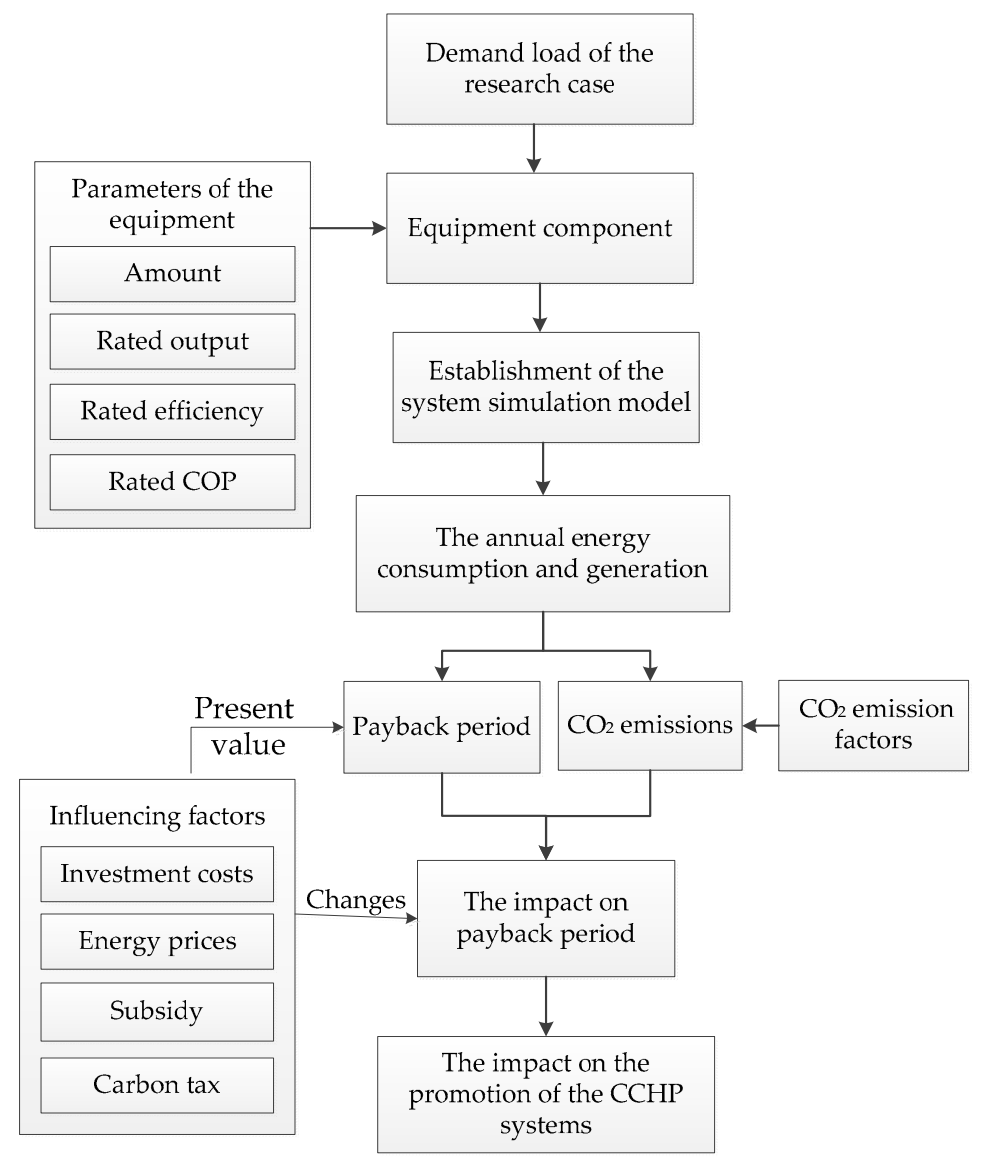

Figure 1. Diagram of the research flow.

The purpose of this study was to analyze the impacts of the investment cost, energy prices, subsidies and carbon tax on the economic performance of the CCHP system, which could significantly improve its promotion. Therefore, the hypotheses were: (1) There is no transmission consumption; the cold, heat and electricity obtained by the simulation can be $100 \%$ used. (2) Ignore the thermal inertia in the process of cold and heat supply and consider that the start and stop of the equipment is consistent with the change in demand load. (3) The parasitic electric energy consumption of the CCHP system (considering the auxiliary equipment required for energy supply and the daily power needs of the system) is estimated to be $10 \%$ of the electricity generation of the CCHP system [24].

This paper is organized as follows. Section 2 presents the mathematical analysis of the energy flow of the CCHP system and proposes evaluation criteria for CCHP systems. Section 3 introduces the research case and establishes the simulation model. Section 4 compares the economic and environmental 
performance of different systems and analyzes the impact of different factors. The conclusion is given in Section 5.

\section{Method}

To analyze the economic performance of the CCHP system, assessment of the energy flow of the CCHP system was carried out to calculate the energy consumption and generation. After that, the economic and environmental performance of the CCHP system could be obtained.

According to the literature [25-27], the payback period is one of the main indicators to evaluate the economics of a project. The carbon dioxide emissions are usually used to represent the environmental performance of the system [28-30]. To compare the comprehensive performance of different systems, this paper uses the payback period and carbon emissions in a multi-criteria evaluation. Through the carbon tax, the environmental indicator of carbon emissions is integrated into the economic performance of the system. Therefore, the impacts of the changes in different factors on the promotion of the CCHP system can be analyzed by comparison of the payback period.

\subsection{Energy Flow of the CCHP System}

In the CCHP system, the power generation unit (PGU) is driven by natural gas and produces electricity. The high-temperature exhaust gas of the PGU is recovered to accommodate the thermal load for cooling and heating for the demand side. In applications, due to large fluctuations in the load on the demand side, electric chillers and gas boilers are usually used in combination with waste recovery equipment, to satisfy the cooling or heating demand load.

The CCHP system consists of PGUs, absorption units, electric chillers and boilers, and its energy flow is shown in Figure 2.

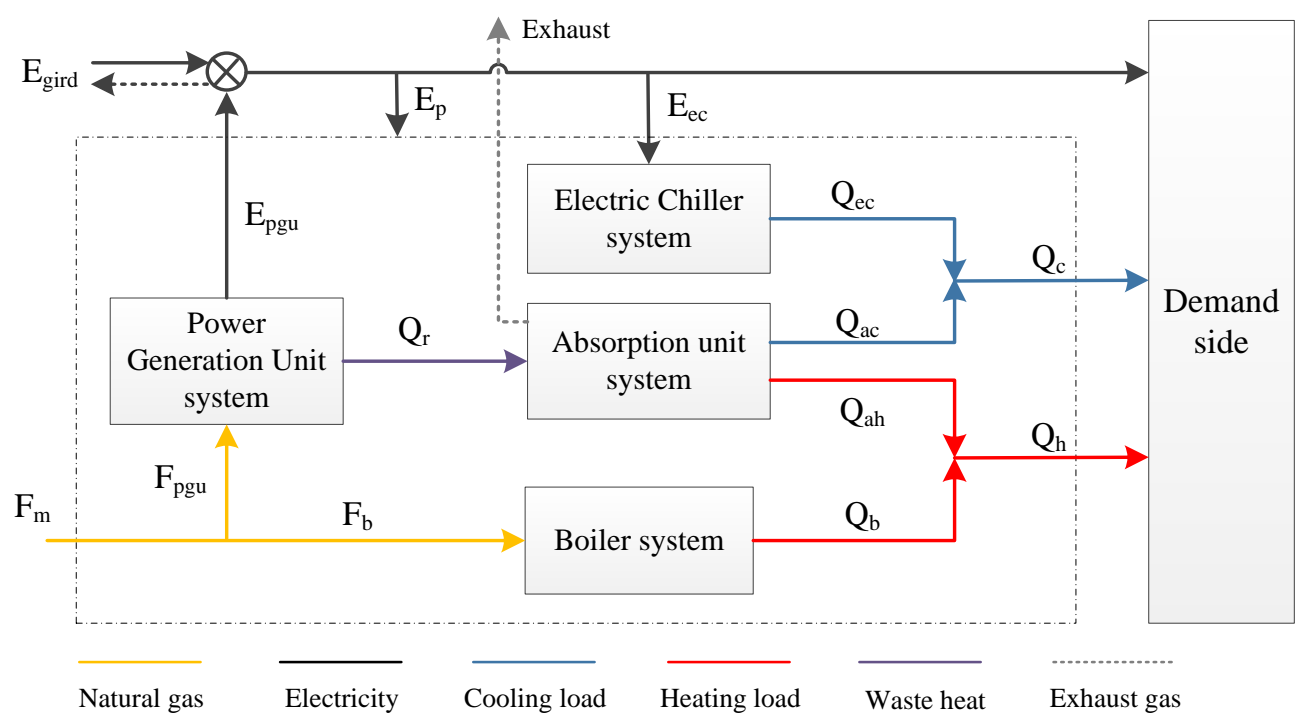

Figure 2. Energy flow diagram of the CCHP system.

The balances of energy in the CCHP system at t-hour are expressed as [30]:

$$
E_{\text {grid }}^{t}+E_{p g u}^{t}=E_{p}^{t}+E_{e c}^{t}+E^{t}
$$

where $E_{\text {grid }}^{t}$ is the electricity from the grid at thour in the CCHP system (when the PGU generates excess electricity, $E_{\text {grid }}^{t}$ is negative, its value is equal to the excess electricity in $\mathrm{kWh}$ and the electricity is sold back to the grid). $E_{p g u}^{t}$ is the electricity generated by the PGU in $\mathrm{kWh}$. $E_{p}^{t}$ is the parasitic electric energy consumption of the CCHP system (considering the auxiliary equipment required for the energy supply and the daily power needs of the system) in $\mathrm{kWh} . E_{e c}^{t}$ is the electric energy consumption for 
electric chillers providing cooling to the demand side in $\mathrm{kWh} . E^{t}$ is the electric energy load of the demand side in $\mathrm{kWh}$.

The fuel energy consumption $\left(F_{p q u}^{t}\right)$ and the waste heat $\left(Q_{r}^{t}\right)$ generation of the PGU at t-time can be calculated as Equations (2) and (3), respectively.

$$
\begin{gathered}
F_{p g u}^{t}=E_{p g u}^{t} / \eta_{e}^{t} \\
Q_{r}^{t}=F_{p g u}^{t} \times \eta_{r e c}^{t} \times\left(1-\eta_{e}^{t}\right) \\
\eta_{e}^{t}=a_{0}+a_{1} \times P L_{p g u}+a_{2} \times P L_{p g u}^{2} \\
\eta_{r e c}^{t}=b_{0}+b_{1} \times P L_{p g u}+b_{2} \times P L_{p g u}^{2}
\end{gathered}
$$

where $E_{p g u}^{t}$ is the electricity generated by the PGU at t-time in kWh. $\eta_{e}^{t}$ is the electric efficiency percentage of the $P G U$ at t-time. $\eta_{r e c}^{t}$ is the heat recovery system efficiency percentage. $P L_{p q u}$ is the part load ratio percentage of the PGU. Equations (4) and (5) are quadratic fitting formulas which can be estimated by the parameters of the actual devices [21].

The waste heat generated by the PGU can be used for cooling or heating. Therefore, the cooling load or heating load produced by the absorption units are estimated, respectively, as

$$
\begin{aligned}
& \text { For cooling, } Q_{a c}^{t}=Q_{r}^{t} \times C O P_{a c}^{t} \\
& \text { For heating, } Q_{a h}^{t}=Q_{r}^{t} \times C O P_{a h}^{t} \\
& C O P_{a}^{t}=c_{0}+c_{1} \times P L_{a}+c_{2} \times P L_{a}^{2}
\end{aligned}
$$

where $Q_{r}^{t}$ is the waste heat generated by the PGU in kWh. $Q_{a c}^{t}$ and $Q_{a h}^{t}$ are the cooling load and heating load produced by the absorption units, respectively, in $\mathrm{kWh}$. $C O P_{a c}^{t}$ is the coefficient of performance (COP) of the absorption units for cooling. COP ${ }_{a h}^{t}$ is the coefficient of performance (COP) of the absorption units for heating. $P L_{a}$ is the part load ratio percentage of the absorption unit. Equation (8) includes the quadratic fitting formulas, which can be estimated by the parameters of the actual devices [21].

The balance of the cooling load is expressed as:

$$
\begin{aligned}
& Q_{a c}^{t}+Q_{e c}^{t}=Q_{c}^{t} \\
& Q_{a h}^{t}+Q_{b}^{t}=Q_{h}^{t}
\end{aligned}
$$

where $Q_{a c}^{t}$ is the cooling produced by the absorption units in $\mathrm{kWh}$. $Q_{e c}^{t}$ is the cooling produced by the electric chillers in $\mathrm{kWh}$. $Q_{c}^{t}$ is the cooling load of the demand side in $\mathrm{kWh}$. $Q_{a h}^{t}$ is the heating produced by the absorption units in $\mathrm{kWh}$. $Q_{b}^{t}$ is the heating produced by the boilers in $\mathrm{kWh}$. $Q_{h}^{t}$ is the heating load of the demand side in $\mathrm{kWh}$.

The electricity used by the electric chiller is calculated as:

$$
E_{e c}^{t}=\frac{Q_{e c}^{t}}{C O P_{e c}^{t}}
$$

where $\mathrm{COP}_{e c}$ is the electric chiller's COP.

The supplementary fuel energy consumption to the boiler, $F_{b}$, can be estimated as:

$$
F_{b}^{t}=\frac{Q_{b}^{t}}{\eta_{b}}=\frac{Q_{h}^{t}-Q_{a h}^{t}}{\eta_{b}}
$$

where $\eta_{b}$ is the boiler efficiency percentage. 


\subsection{Evaluation Criteria}

\subsubsection{Economic Analysis}

\section{(1) Annual total profit (ATP)}

The annual total profit (ATP), which is the energy income minus the annual energy cost and operation and maintenance cost, is calculated as follows:

$$
A T P=\sum_{t=1}^{8760}\left[Q_{c}^{t} \times E C_{c}^{t}+Q_{h}^{t} \times E C_{h}^{t}\right]+\sum_{t=1}^{8760}\left[E^{t} \times E C_{e}^{t}\right]-\sum_{t=1}^{8760}\left(E_{\text {grid }}^{t} E C_{e}^{t}+F_{m}^{t} E C_{f}^{t}\right),
$$

where $E C_{c}^{t}, E C_{h^{\prime}}^{t} E C_{e}^{t}$ and $E C_{f}^{t}$ are the energy price of cooling, heating, electricity and natural gas at t-hour, respectively, in $\$ / \mathrm{kWh}$.

(2) Investment cost

The investment cost is spent at the beginning when purchasing the equipment in the construction of the system, calculated as follows:

$$
I N=\sum_{n=1}^{N}\left(C_{p g u} \times N C_{n}\right)+\sum_{n=1}^{N}\left(C_{a b} \times N C_{n}\right)+\sum_{m=1}^{M}\left(C_{e c} \times N C_{m}\right)+\sum_{i=1}^{I}\left(C_{b} \times N C_{i}\right),
$$

where $C_{p g u}, C_{a b}, C_{e c}$ and $C_{b}$ are the equipment unit cost of the PGU, absorption unit, electric chiller and boiler, respectively, in $\$ / \mathrm{kW} . N C_{n}, N C_{m}$ and $N C_{i}$ are the nominal capacity of the PGU, electric chiller and boiler, respectively, in $\mathrm{kW} . \mathrm{N}, \mathrm{M}$ and I are the number of PGUs, electric chillers and boilers. The absorption unit should be matched with the PGU, so the number is the same as for the PGU.

(3) Dynamic payback period (PB)

The payback period, an index of economic performance, is the time required for the project to recover the initial investment cost. By calculating payback period, the economic performance of the projects can be compared. A short payback period means that the economic benefits of the system are high. The dynamic payback period is calculated when the cumulative net present value (NPV) is zero, as shown by Equation (16).

$$
N P V(n)=0 \quad \rightarrow \quad P B=n
$$

The payback period cannot be longer than the lifetime of the system, which is 25 years in this paper.

The net present value (NPV) is the difference between the present value of cash inflows and the present value of cash outflows during a period, which mainly represents the balance between the present value of total profit and the initial investment. It can be expressed as [26]:

$$
N P V=\sum_{n=1}^{P B} \frac{A T P_{n}}{(1+i)^{n}}-I N
$$

where $A T P_{n}$ is the annual total profit in dollars. $i$ is the discount rate percentage. IN is the total investment cost in dollars.

\subsection{2. $\mathrm{CO}_{2}$ Emission Analysis}

The amount of carbon dioxide emissions (CDEs) from the CCHP system can be determined using the emission conversion factors as follows [29,30]:

$$
\mathrm{CDE}=\sum_{t}^{8760} E_{\text {grid }}^{t} \times \mu_{\mathrm{CO}_{2}, e}+\sum_{t}^{8760} F_{m}^{t} \times \mu_{\mathrm{CO}_{2}, \mathrm{gas}}
$$


where $\mu_{\mathrm{CO}_{2}, e}$ and $\mu_{\mathrm{CO}_{2}, \text { gas }}$ are the emission conversion factors for electricity from the grid and natural gas, respectively, in $\mathrm{g} / \mathrm{kWh}$.

A carbon tax is one of the effective means to reduce carbon emissions. At present, at least 20 countries in the world have imposed carbon taxes [31]. The carbon tax can be calculated into the total annual profit, as follows:

$$
A T P^{\prime}=A T P-\triangle C D E \times T_{a x} \mathrm{co}_{2}
$$

where $A T P^{\prime}$ is the total annual profit considering the carbon tax. $\triangle C D E$ is the difference in carbon dioxide emissions before and after utilization of the energy supply system. Tax $\mathrm{CO}_{2}$ is the carbon tax.

\section{Case Study}

A typical CCHP system in an amusement park resort in Shanghai, China, was taken as a research case, and its economic performance was analyzed. As the first CCHP system under stable operation in China, its equipment selection, system design and operation strategy are highly representative and universal. At the same time, it provides electricity, cooling and heating for the demand side with different load characteristics. Based on this research case, the study of the impacts of different factors on the promotion of CCHP system in China is valuable.

Generally, centralized energy supply systems with electric chillers and gas boilers are commonly used in amusement parks to provide cooling and heating [32]. Nowadays, a few major theme park companies are embracing a more energy-saving and environmentally friendly way to solve energy problems. The CCHP system is an alternative to conventional systems. The research case of this paper is a hybrid CCHP system with penetration of $50 \%$ (the cooling and heating load provided by waste heat from PGUs account for $50 \%$ of the total demand). To study the promotion of CCHP systems, this paper proposes three CCHP systems with different penetration rates, using the current system for comparison:

System 1 (conventional system): without CCHP (only adopting electric chillers and boilers to supply cooling and heating load, the electricity is from the utility grid);

System 2 (current system): CCHP with 50\% penetration (adopting PGUs, absorption units, electric chillers and boilers to cooperate to supply electricity, cooling and heating); and

System 3 (target system): CCHP with 100\% penetration (only adopting PGUs and absorption units to supply energy).

By comparing the above three CCHP systems with different penetration, the economics and environmental performance of the CCHP system were analyzed, and the impacts of different factors could be discussed.

\subsection{The Information on the Research Case}

\subsubsection{System Configuration}

Due to the large electricity load of the resort, the CCHP system is operated following thermal demand, and the excess electricity can be sold back to the grid. The system makes full use of waste heat from PGU to provide cooling and heating load for the resort.

In the CCHP system, the PGU adopts a gas internal combustion engine (ICE). The waste recovery equipment adopts a flue gas hot water-type lithium bromide absorption heat transformer unit (absorption unit), which can produce cooling or heating. Electric chillers and gas-fired boilers are employed to operate with the absorption unit to meet the cooling and heating needs of the tourism resort. The penetration of this CCHP system is 50\%. The configuration of the CCHP system with 50\% penetration is shown in Table 1. After investigating and consulting the equipment manufacturers, the characteristic parameters of these equipment of this CCHP system are listed in Table 2. 
Table 1. The configuration of the CCHP system with $50 \%$ penetration.

\begin{tabular}{cccc}
\hline Equipment & Type & Amount & Rated Output(kW) \\
\hline ICE & JMS624GS & 5 & 4401 \\
Absorption unit & YRXII368 & 5 & 3931 \\
Electric chiller 1 & YKR2R2K45DGG & 4 & 6330 \\
Electric chiller 2 & YKK8K4H95CWG & 2 & 3165 \\
Boiler & FBD-7.0-1.0/90/65.5 & 2 & 7000 \\
\hline
\end{tabular}

Table 2. The characteristic parameters of the CCHP system with $50 \%$ penetration.

\begin{tabular}{cccc}
\hline Equipment & Variable & Symbol & Rated Value \\
\hline ICE & Efficiency & $\eta_{e}$ & 0.45 \\
Electric chiller & COP & $C O P_{e}^{t}$ & 5.353 \\
Absorption unit & COP & $\mathrm{COP}_{a}^{t}$ & 1 \\
Boiler & Efficiency & $\eta_{b}$ & 0.98 \\
\hline
\end{tabular}

To compare the economic and environmental performance of the three different systems, we adopted the same equipment for the conventional system (without CCHP) and CCHP system with $100 \%$ penetration. The energy generated by these three systems can meet the same cooling and heating load. Other characteristic parameters of the equipment are the same as in the CCHP system with $50 \%$ penetration. The configurations of the three systems are listed in Table 3.

Table 3. The configurations of the conventional system without CCHP and the CCHP system with $100 \%$ penetration.

\begin{tabular}{ccccc}
\hline System & Equipment & Type & Amount & Rated Output(kW) \\
\hline \multirow{2}{*}{ Conventional system } & Electric chiller 1 & YKR2R2K45DGG & 6 & 6330 \\
(without CCHP) & Electric chiller 2 & YKK8K4H95CWG & 4 & 3165 \\
The CCHP system with & Boiler & FBD-7.0-1.0/90/65.5 & 4 & 7000 \\
100\% penetration & ICE & JMS624GS & 15 & 4401 \\
& Absorption unit & YRXII368 & 15 & 3931 \\
\hline
\end{tabular}

\subsubsection{Load Curve}

The total area of the amusement park resort in Shanghai is $116 \mathrm{~km}^{2}$. There are two themed hotels, many amusement facilities and many restaurants and shopping stores in the resort. The total construction area of these two themed hotels is $161,000 \mathrm{~m}^{2}$. Through the pipe network system and cables, the CCHP system provides cold, heat and electricity to the resort. Because the CCHP system is operated following the thermal demand and the excess electricity can be sold back to the grid, the cooling and heating load should be satisfied preferentially. The hourly cooling and heating load demand from January 2016 to December 2016 of the resort is shown in Figure 3, and the following characteristics can be derived:

1. Both cooling load and heating load are required throughout the year.

2. The cooling load peak is greater than the heating load peak because of the hot climate of Shanghai.

3. The cooling load is high and the heating load is low in summer. The heating load is high and the cooling load is low in winter.

4. Mid-season, the energy demands for cooling and heating are similar. 


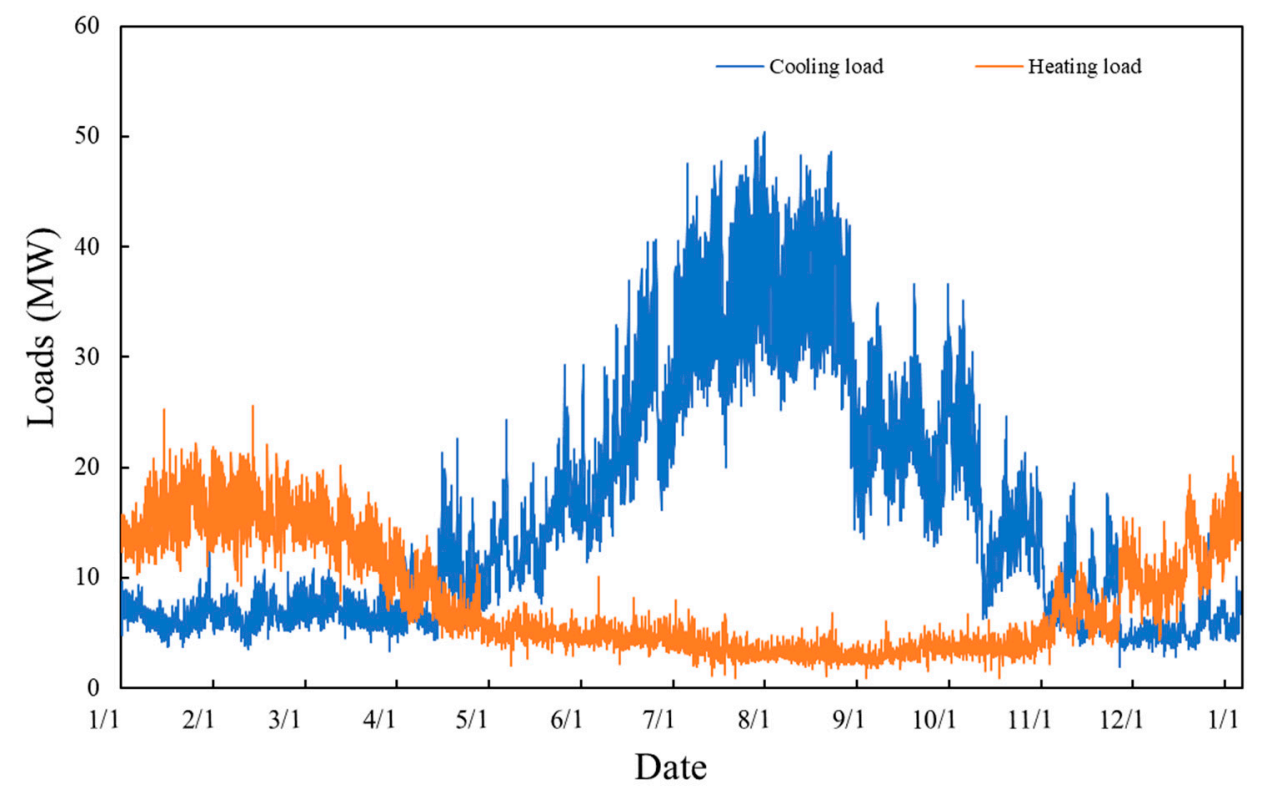

Figure 3. The hourly cooling and heating loads.

\subsection{Simulation Model}

\subsubsection{Establishment of Simulation Model}

We used TRNSYS $[33,34]$ to establish the operation simulation model of the CCHP systems. Through adjusting and connecting the system components, including ICEs, absorption units, electrical chillers, gas boilers and other auxiliary equipment, the operation model of the CCHP system was established to simulate instantaneous energy consumption and generation, as shown in Figure 4. $\mathrm{N}$ is the number of ICEs/absorption units, $\mathrm{M}$ is the number of electric chillers and I is the number of boilers in the diagram, which are listed in Table 4.

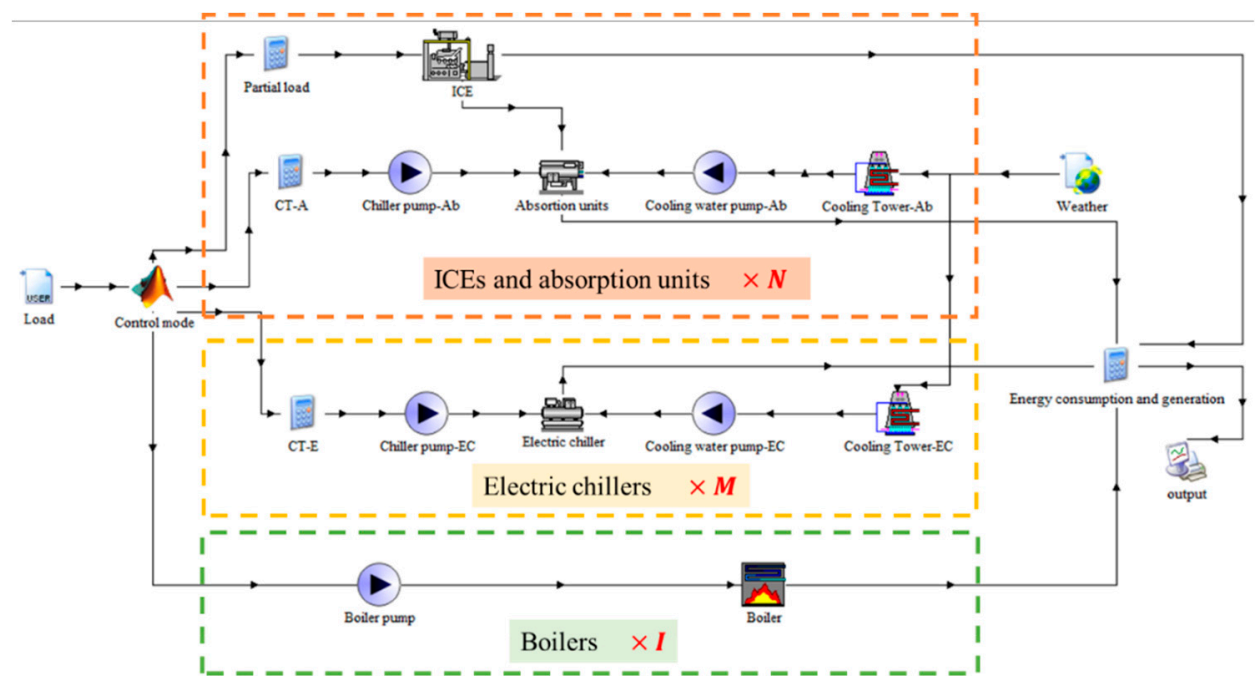

Figure 4. The simulation diagram of operation mode. 
Table 4. The numbers of various types of equipment in the three systems.

\begin{tabular}{cccc}
\hline System & N & M & I \\
\hline Conventional system (without CCHP) & 0 & 10 & 4 \\
The CCHP system with 50\% penetration & 5 & 5 & 2 \\
The CCHP system with 100\% penetration & 15 & 0 & 0 \\
\hline
\end{tabular}

\subsubsection{Setting of Partial Load Performance and Validation of the Simulation Model}

The number of units started is determined based on the load change at the previous moment. Therefore, the start and stop sequence of each piece equipment was simulated in MATLAB. The part load ratio $\varepsilon$ of units is:

$$
\varepsilon \in[0,1]
$$

Each module was set according to the actual performance of the equipment. The partial load performance of the ICE, absorption unit and electric chiller were set by an external file according to the specifications provided by the manufacturer, as shown in Table 5 and Figure 5. The weather conditions of Shanghai are obtained through the typical meteorological year (TMY2) module, which can make the simulated environment consistent with the actual operating environment.

Table 5. The partial load data of the ICE (external file).

\begin{tabular}{ccccc}
\hline Partial Load Output Rate & $\mathbf{3 7 \%}$ & $\mathbf{5 0 \%}$ & $\mathbf{7 5 \%}$ & $\mathbf{1 0 0 \%}$ \\
\hline Mechanical efficiency & 0.408 & 0.421 & 0.443 & 0.45 \\
Electrical efficiency & 0.965 & 0.97 & 0.977 & 0.978 \\
Cylinder water waste heat ratio & 0.23 & 0.266 & 0.324 & 0.339 \\
Total oil excess heat & 0.11 & 0.105 & 0.084 & 0.071 \\
Emissions waste heat ratio & 0.49 & 0.468 & 0.449 & 0.425 \\
Medium cooler waste heat ratio & 0.09 & 0.09 & 0.09 & 0.12 \\
Environmental waste heat ratio & 0.08 & 0.071 & 0.053 & 0.045 \\
Exhaust capacity rated & 0.48 & 0.57 & 0.77 & 1 \\
\hline
\end{tabular}

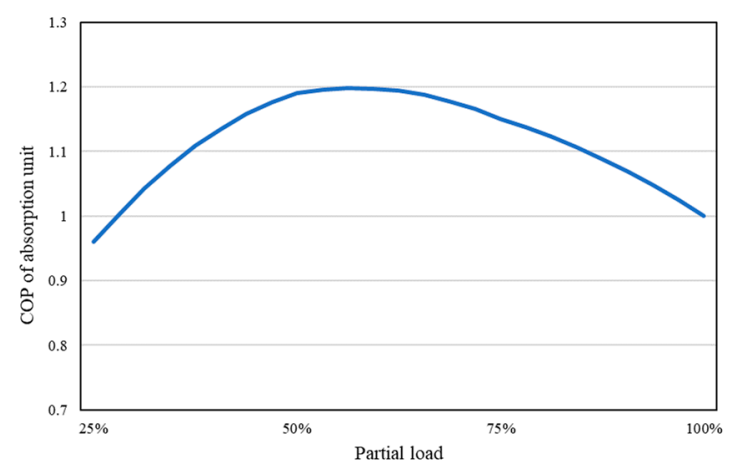

(a)

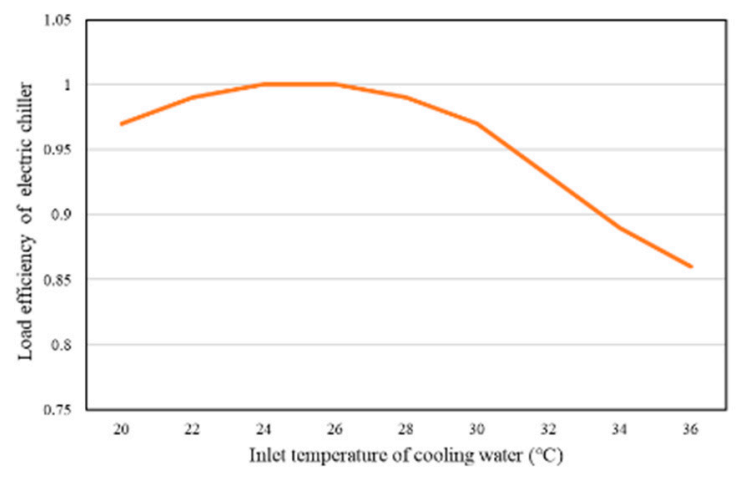

(b)

Figure 5. The performance of the absorption unit and electric chiller under partial load: (a) the part load performance of the absorption unit; and (b) the load efficiency of the electric chiller.

For accuracy of the simulation, the performance of the model was compared with the actual operation data at full load of System 2, as shown in Table 6. 
Table 6. Validation of simulation results performance with operating parameters at full load of the CCHP system with $50 \%$ penetration.

\begin{tabular}{ccccc}
\hline Equipment & Parameter & Rated Value & Simulation Results & Error Ratio (\%) \\
\hline \multirow{2}{*}{ ICE } & Power generation efficiency $(\%)$ & 45.4 & 44.41 & $2.18 \%$ \\
& Power output $(\mathrm{kW})$ & 4401 & 4400 & $0.02 \%$ \\
& Exhaust temperature $\left({ }^{\circ} \mathrm{C}\right)$ & 368 & 359.6 & $2.28 \%$ \\
\hline \multirow{2}{*}{ Absorption } & Cylinder water outlet temperature $\left({ }^{\circ} \mathrm{C}\right)$ & 95 & 94.88 & $0.13 \%$ \\
Unit & Chilled water outlet temperature $\left({ }^{\circ} \mathrm{C}\right)$ & 6 & 6 & $0.00 \%$ \\
& Cooling capacity $(\mathrm{kW})$ & 3931 & 3922 & $0.22 \%$ \\
& Heating capacity $(\mathrm{kW})$ & 3931 & 3922 & $0.22 \%$ \\
Electric & Cooling water outlet temperature $\left({ }^{\circ} \mathrm{C}\right)$ & 38 & 38.2 & $-0.53 \%$ \\
chiller & Cooling capacity $(\mathrm{kW})$ & 6330 & 6315 & $0.23 \%$ \\
\hline Boiler & Chilled water outlet temperature $\left({ }^{\circ} \mathrm{C}\right)$ & 6 & 6 & $0.00 \%$ \\
\hline
\end{tabular}

In Table 6, we can see that the relative errors are within $3 \%$ after comparing the simulation results with actual data. This demonstrates that the results simulated by the model are in good agreement with the actual operational data.

\section{Results and Discussion}

\subsection{Simulation Results of the Energy Consumption and Generation}

After simulating with the TRNSYS model, the hourly energy consumption and generation of the three systems were obtained. To comprehensively explain the operation situation of all equipment, the CCHP system with $50 \%$ penetration was taken as an example for analysis and description.

In the CCHP system with 50\% penetration, the absorption units and electric chillers are operated cooperatively to meet the cooling load of demand side. The simulation model of the CCHP system with $50 \%$ penetration was established according to Section 3.2, with the parameters outlined in Tables 1 , 2 and 4 . The hourly cooling supply and demand balance of the system in summer is illustrated in Figure 6. We obtained the hourly energy consumption and generation from the output of the TRNSYS model, as shown in Figure 7. A positive value indicates energy generation and a negative value indicates energy consumption. Because the cooling load is high in summer, all the ICEs and absorption units are turned on at full load to supply the cooling load. An insufficient cooling load is supplemented by the electric chillers. Therefore, electricity is consumed by the electric chillers and other auxiliary equipment. The excess electricity is sold back to the grid.

The monthly energy consumption and generation over one year is shown in Figure 8. The solid line represents energy generation and the dashed line represents energy consumption.

\subsection{Comparison of Economic and Environment Performance in Three Systems}

According to the parameters in Tables 3 and 4 the simulation models of the CCHP systems with different penetrations were established. From the simulation results, we compared the energy consumption and generation of the three systems. Figure 9 shows the seasonal natural gas consumption of the three systems. Figure 10 demonstrates the electricity consumption and generation. 


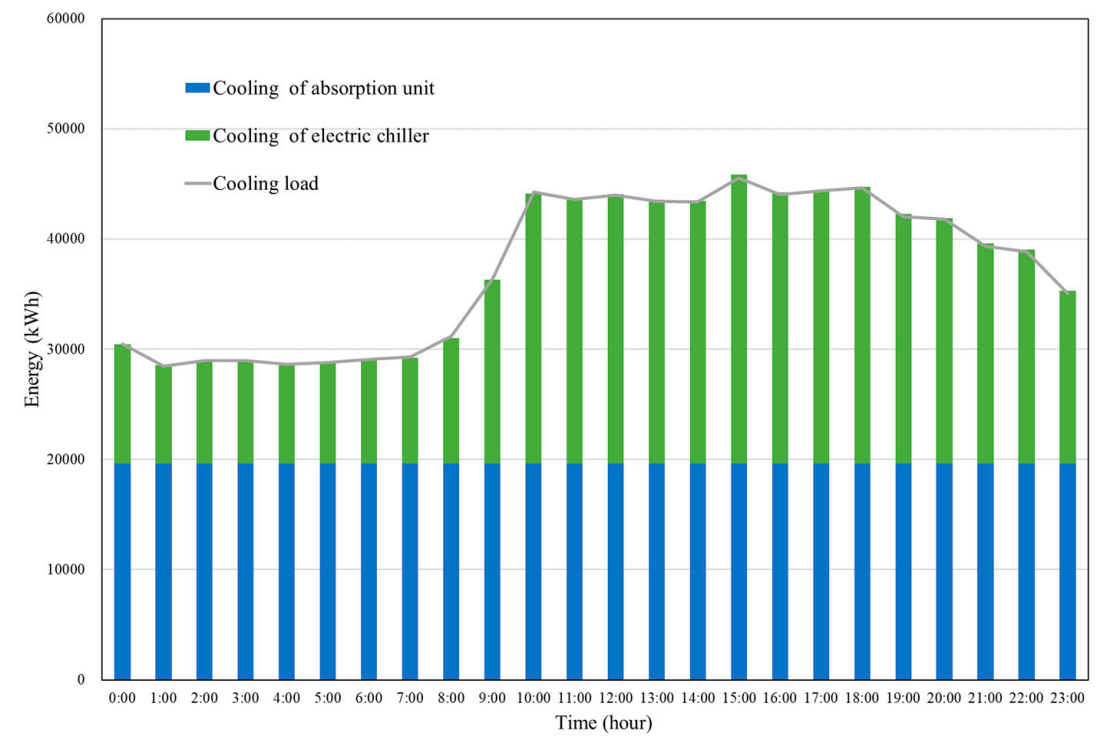

Figure 6. Hourly cooling supply and demand balance in summer.

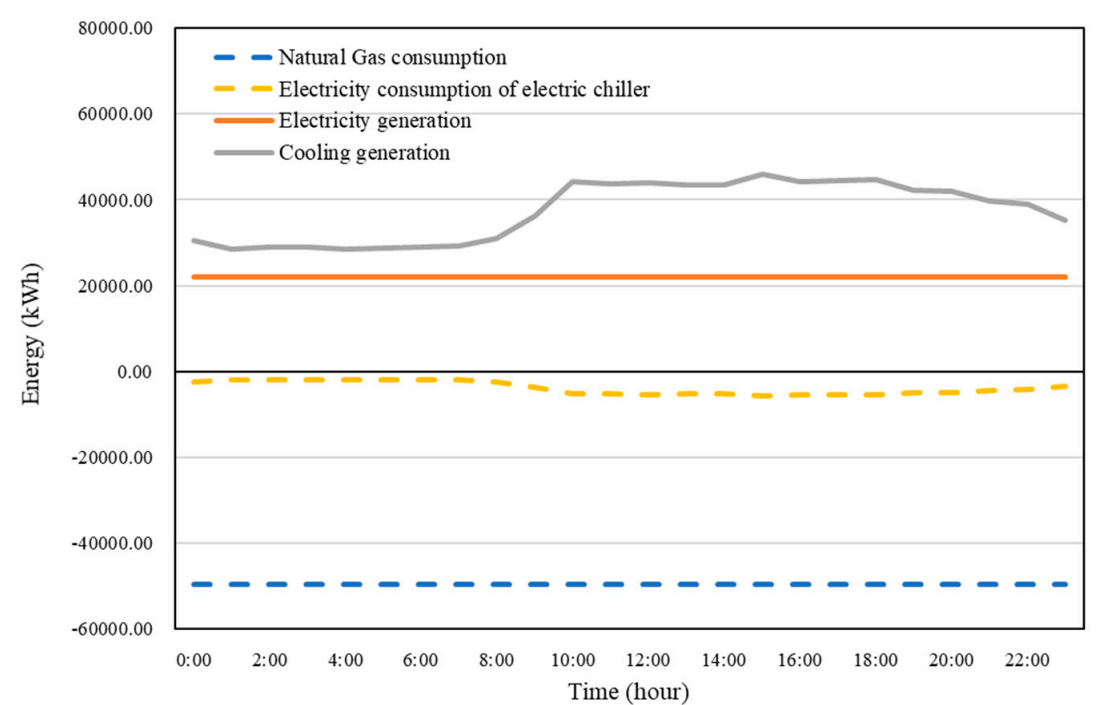

Figure 7. Hourly energy consumption and generation in summer.

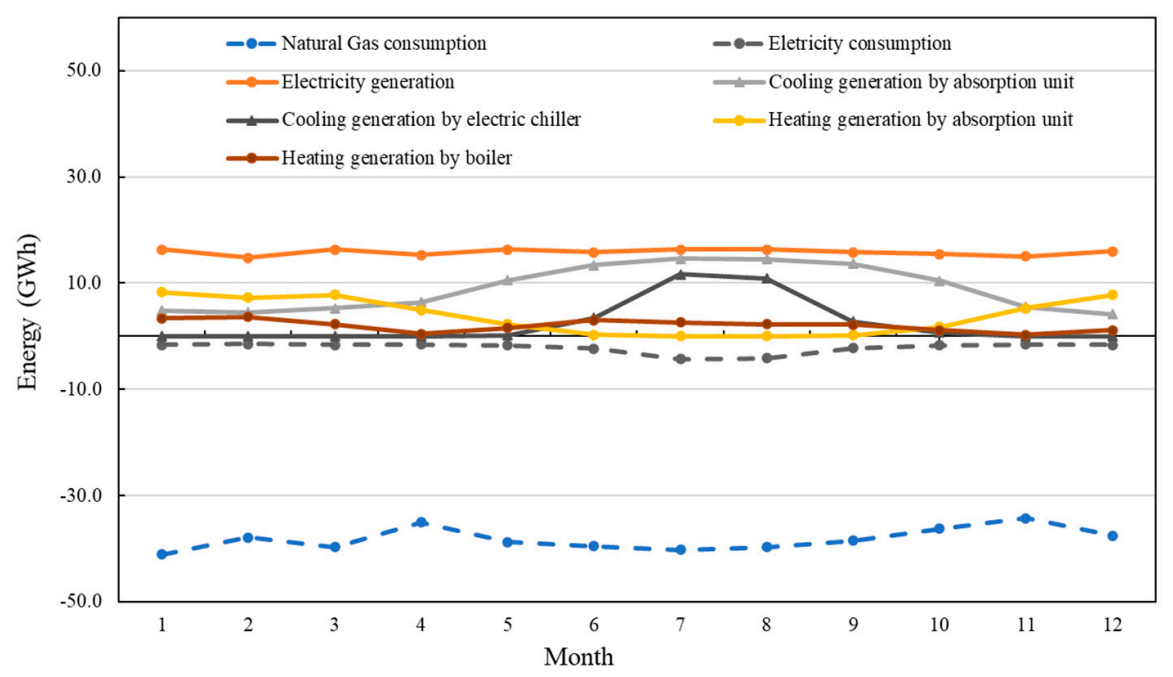

Figure 8. The monthly energy consumption and generation. 


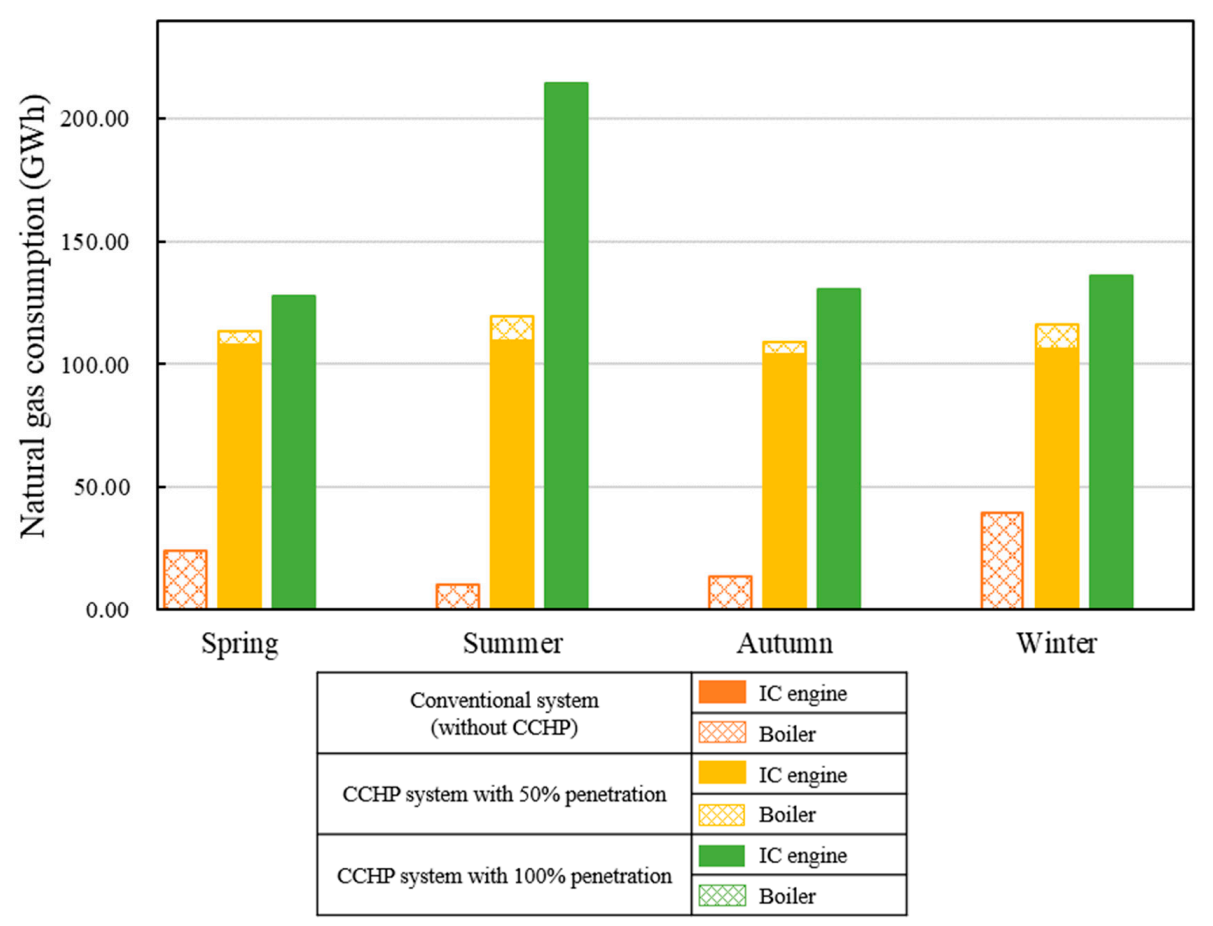

Figure 9. The seasonal natural gas consumption of the three systems simulated in the model.

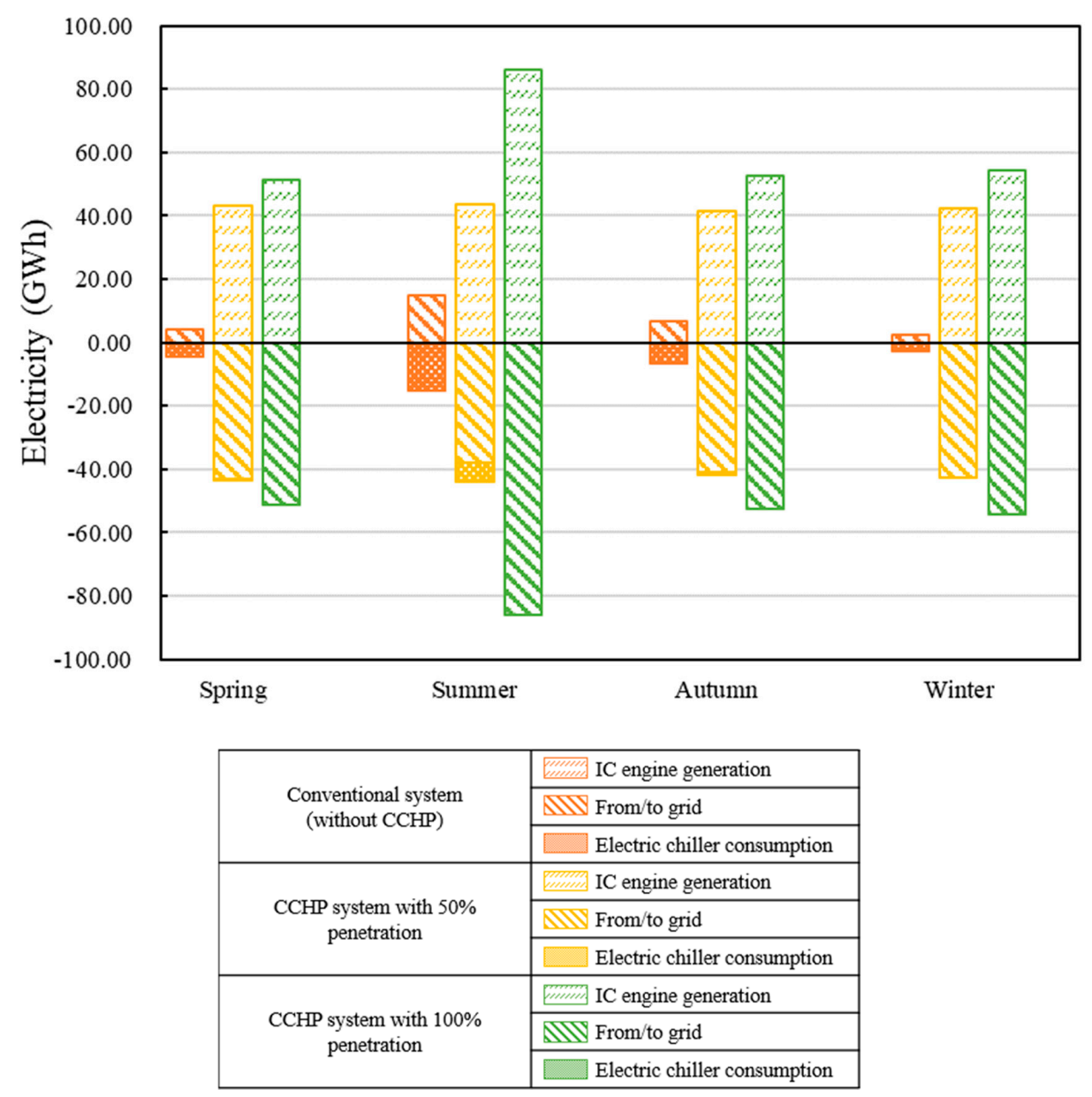

Figure 10. The seasonal electricity consumption and generation of the three systems simulated in the model. 
It can be seen in the above figures that there is excess electricity sold back to the grid in the CCHP systems with $50 \%$ and $100 \%$ penetration because the electricity from the grid is negative. The electricity from the grid consumption of the conventional system (without CCHP) is the highest, because it only uses electric chillers to supply cooling. The natural gas consumption and power generation of the CCHP system with $100 \%$ penetration are the highest.

According to the investigation, the equipment, energy prices and other parameters of the Shanghai CCHP system are shown in Table 7.

Table 7. The facility price, energy price and other parameters of the CCHP system.

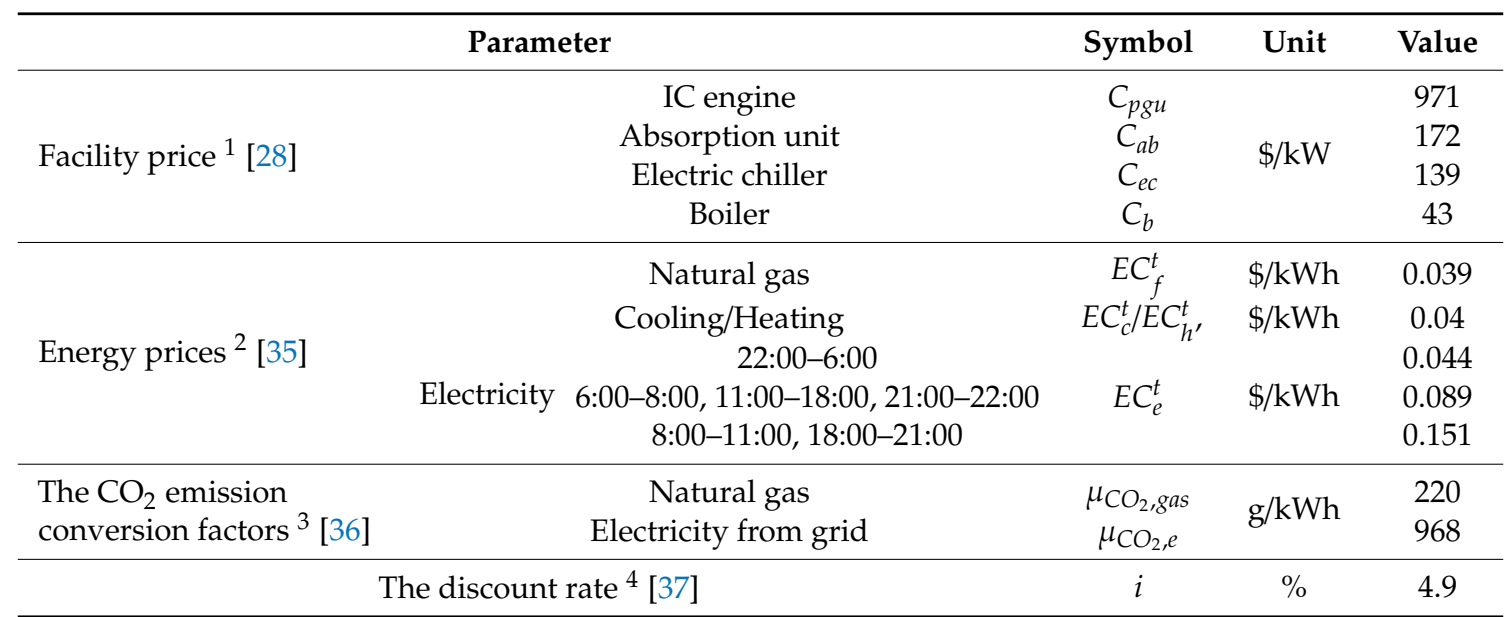

${ }^{1}$ The facility prices were determined according to the Li. [28] in 2020. ${ }^{2}$ Energy prices were determined according to the present energy prices in Shanghai in $2020 .{ }^{3}$ The $\mathrm{CO}_{2}$ emission conversion factors were determined according to the Khodaei. [36] in 2018. ${ }^{4}$ The discount rate was determined by the benchmark lending rate set by the People's Bank of China in 2017.

Based on the simulation results, the economic and environmental performances are shown in Tables 8 and 9. The comparison of the payback period and $\mathrm{CO}_{2}$ emissions of the three different systems is shown Figure 11.

Table 8. The economic performance of the three systems.

\begin{tabular}{cccc}
\hline Systems & ATP (\$) & IN (\$) & Payback Period (year) \\
\hline Conventional system (without CCHP) & 2.28 & 8.3 & 4.01 \\
CCHP with 50\% penetration & 5.35 & 29.8 & 6.5 \\
CCHP with 100\% penetration & 7.09 & 74.2 & 14.67 \\
\hline
\end{tabular}

Table 9. The environmental performance of the three systems.

\begin{tabular}{ccccc}
\hline Systems & $\begin{array}{c}\text { Natural } \\
\text { Consumption } \\
\text { (GWh) }\end{array}$ & $\begin{array}{c}\text { Electricity } \\
\text { Consumption } \\
\text { (GWh) }\end{array}$ & $\begin{array}{c}\text { Electricity } \\
\text { Generation } \\
\text { (GWh) }\end{array}$ & $\begin{array}{c}\mathbf{C O}_{\mathbf{2}} \\
\text { Emissions } \\
\text { (ton) }\end{array}$ \\
\hline Conventional system (without CCHP) & 87.42 & 135.49 & 0.00 & 150,390 \\
CCHP with 50\% penetration & 457.91 & 132.50 & 190.00 & 45,080 \\
CCHP with 100\% penetration & 609.33 & 134.05 & 271.46 & 1030 \\
\hline
\end{tabular}




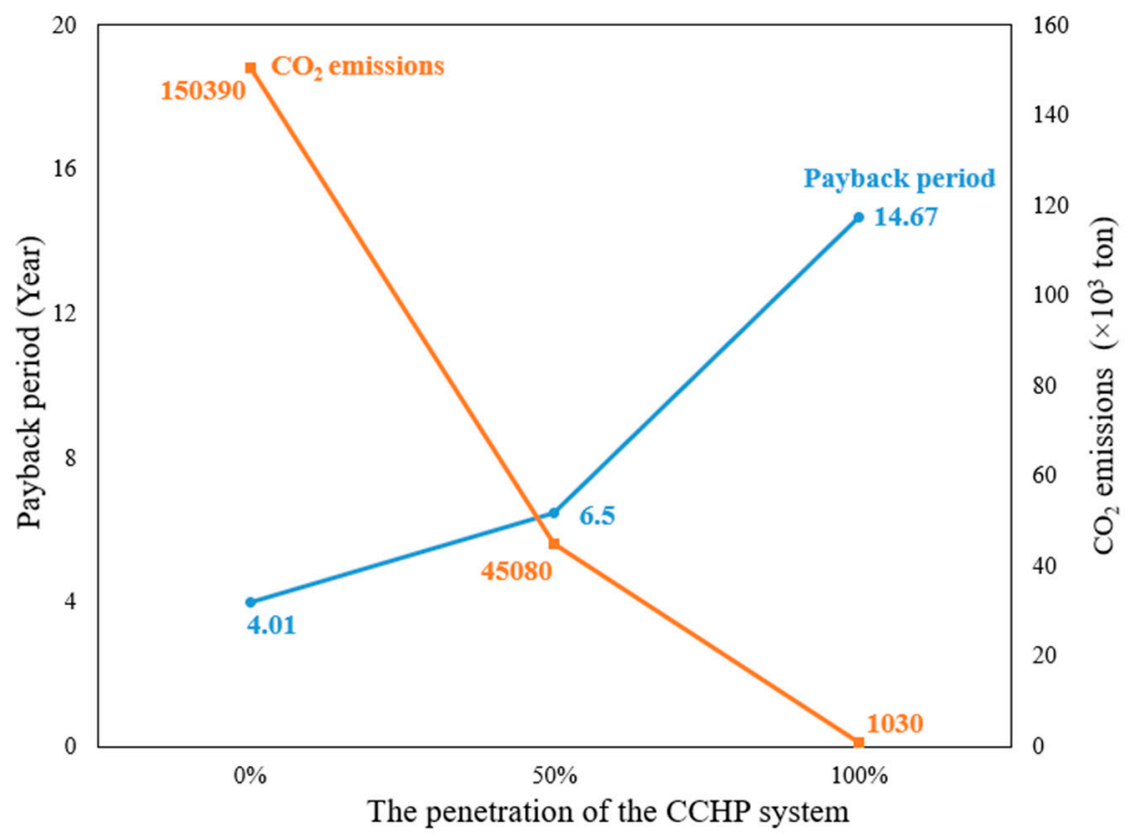

Figure 11. The economic and environmental performance of the CCHP system with different penetration rates.

As shown in Table 8 and Figure 11, although the annual total profit is better after adopting the $\mathrm{CCHP}$ system, the economic performance is worse as the penetration of the CCHP system increases. This is because the payback period is postponed with the increase of investment in the CCHP system. In Table 9 and Figure 11, we can see that the amount of carbon emissions is significantly reduced with higher penetration of the CCHP system. This is because the CCHP system uses natural gas as fuel, and the excess electricity generated by ICEs could be sold back to the grid and completely consumed by users. The power generated by clean energy, with high power generation efficiency, replaces the same amount of electricity from the grid which is produced by coal power plants. Therefore, to comprehensively consider the performance gap between systems with different penetration, the carbon tax was introduced to convert the environmental advantages of the CCHP system into economic advantages for comparison in the follow-up research.

\subsection{Impact of Different Factors on the Economic Performance of CCHP System}

We analyzed the economic influence factors of the CCHP system and compared the economic performance of the three CCHP systems with different penetration rates with various changes in these factors.

Investment cost is one of the main factors affecting the economics of the CCHP system. In the future, as the cost of the CCHP system decreases, its economy will gradually improve. Energy prices determine the operation cost and profit of the CCHP system, which directly reflect the economic performance of the CCHP system. Supportive policy is one of the most effective measures that can contribute to the economics of the CCHP system. At present, an investment subsidy is available in Shanghai [13]. This investment subsidy is a direct grant provided by the government according to the installed capacity of the CCHP system during construction. With reasonable subsidies, the attraction of the investment into and installed capacity of the CCHP system can be improved. With an emphasis on energy saving and emissions reduction, the implementation of a carbon tax can increase the operation cost of an energy system, because the energy becomes more expensive when imposing taxes on fossil energy consumption. Compared with the conventional system, the advantage of the CCHP system would be more obvious after employing a carbon tax due to the low emission character. 
Therefore, how the above factors affect the economics of the CCHP system are discussed below. The influencing factors and values are shown in Table 10.

Table 10. The changes in factors on the economic performance of CCHP system.

\begin{tabular}{|c|c|c|}
\hline \multicolumn{2}{|c|}{ Factors } & Changes \\
\hline \multicolumn{2}{|c|}{ Penetration of CCHP system } & $0 \%, 50 \%, 100 \%$ \\
\hline \multicolumn{2}{|c|}{ Investment cost decrease } & $0 \%$ to $100 \%$ \\
\hline \multirow{2}{*}{ Energy price } & Electricity price & $-50 \%$ to $50 \%$ \\
\hline & Natural gas price & $-50 \%$ to $50 \%$ \\
\hline \multicolumn{2}{|c|}{ Investment subsidy } & 0 to 2 times the current subsidy ${ }^{1}$ \\
\hline \multicolumn{2}{|c|}{ Carbon tax } & 0 to $50 \$ /$ ton $[38]$ \\
\hline
\end{tabular}

${ }^{1}$ According to the current subsidy policy of the CCHP system in China, the total subsidy is $430 \$ / \mathrm{kW}$ at present (the U.S. dollar exchange rate against RMB is 1:7) [10,39].

(1) Impact of the investment cost on the economic performance of the CCHP system

Because the investment cost of the CCHP system is much larger than that of conventional equipment (electric chiller and gas boiler), the payback period is lengthened as the increase of investment cost in the CCHP system. The impacts of changes in the investment cost on the payback periods of the considered CCHP systems are shown in Figure 11. As shown in Figure 12, the investment of the CCHP system needs to be reduced by $48 \%$ to achieve a shorter payback period for the CCHP system with $50 \%$ penetration, when compared to the conventional system (without CCHP). When the investment cost is reduced by $76 \%$, the economy of the $100 \%$ CCHP system will exceed that of the conventional system (without CCHP).

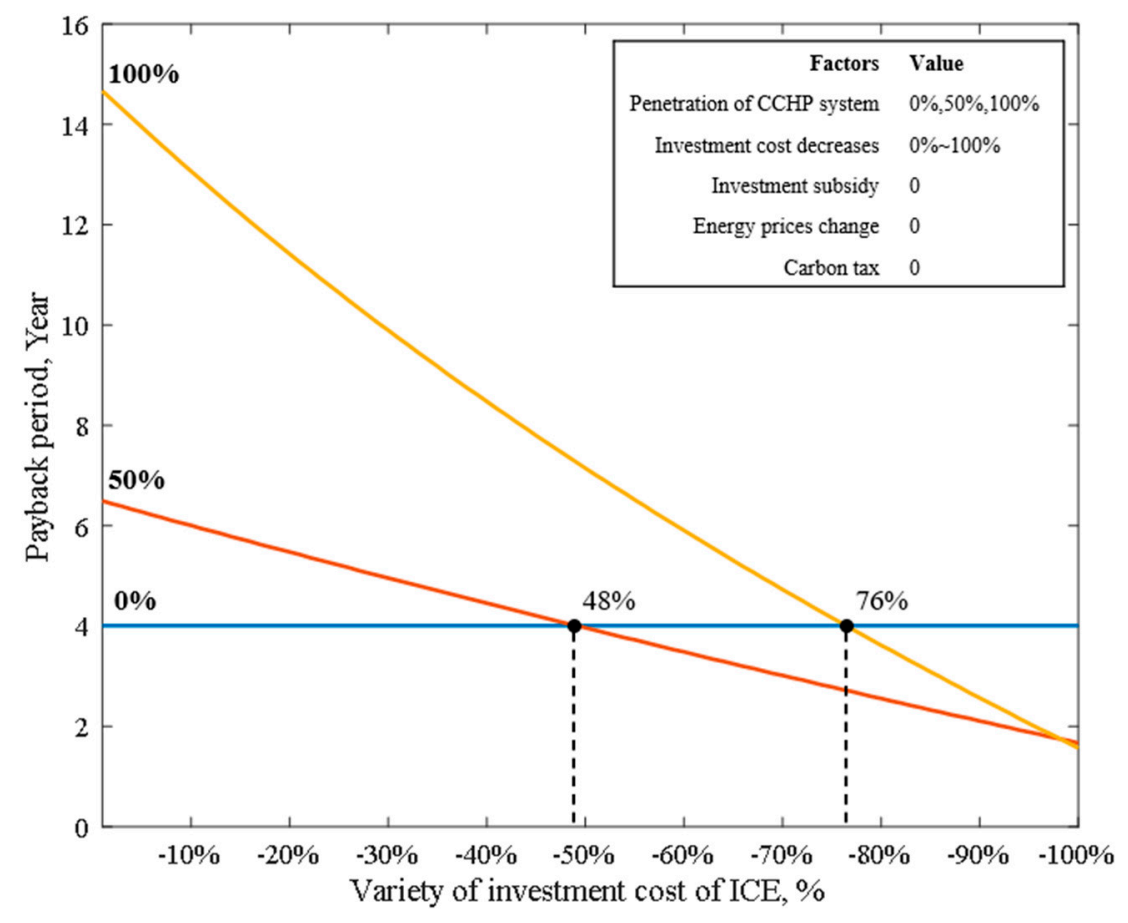

Figure 12. Impacts of investment cost.

(2) Impact of energy prices on the economic performance of the CCHP system

Energy prices determine the operating costs and profits of the system. With an increase of energy price subsidies, the operating profits of the CCHP system can be increased, thereby shortening the 
payback period. Figure 13 presents changes in the payback periods of CCHP systems with different energy prices. The electricity price and natural gas price increase or decrease by $10 \%, 20 \%, 30 \%, 40 \%$ and $50 \%$, respectively.

As shown in Figure 13a, the operating cost of the conventional system (without CCHP) increases with the electricity price, which leads to a longer payback period. On the contrary, the increase in electricity prices brings greater benefits for the CCHP systems with $50 \%$ and $100 \%$ penetration. Therefore, the payback periods of these two CCHP systems decrease as the electricity price increases. When the electricity price increases by more than $11.5 \%$, the payback period of the CCHP system with $50 \%$ penetration can be shorter than that of the conventional system (without CCHP). For the CCHP system with $100 \%$ penetration, the electricity price needs to rise by $30 \%$.

Figure $13 \mathrm{~b}$ shows that, with the changes of natural gas price, the change trends of the payback period of the three systems are the same. As the three systems are all driven by natural gas, the operating costs increase with the increase in natural gas prices, which causes the extension of the payback period. The economic gap between the three systems decreases as the natural gas price reduces. However, even with a 50\% reduction, the payback period of the conventional system (without CCHP) is still optimal.

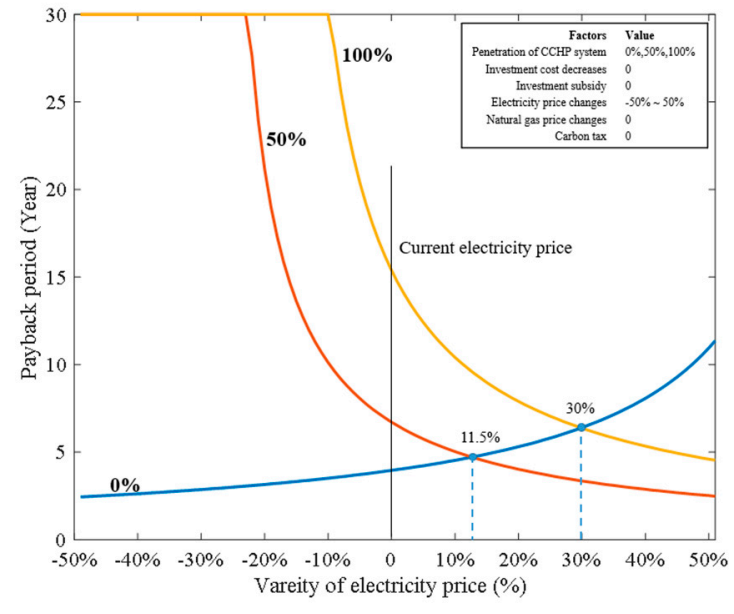

(a)

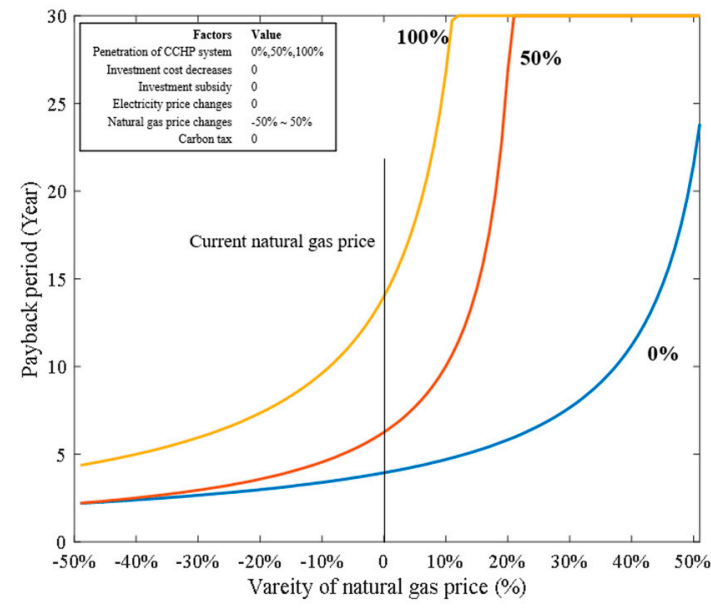

(b)

Figure 13. The impacts of energy prices: (a) electricity price; and (b) natural gas price.

(3) Impact of the investment subsidy on the economic performance of the CCHP system

We considered the current investment subsidy $(430 \$ / \mathrm{kW})$ and increased it by $0-2$ times to analyze the impacts on the payback period of the CCHP systems, as shown in Figure 14.

According to Figure 14, as the investment subsidy increases, the improvement of the economic performance of the CCHP system is significant. Under the current investment subsidy, the payback period of the CCHP system with 50\% penetration is almost the same as that of the conventional system (without CCHP), which indicates that the current subsidy policy can bring economic advantages to the CCHP system. With the increase of investment subsidies, the penetration of the CCHP system can be increased. When the investment subsidy reaches more than $733 \$ / \mathrm{kW}$ (that is, 1.71 times the current subsidy), the $100 \%$ CCHP system will achieve better economic performance than the conventional system (without CCHP). 


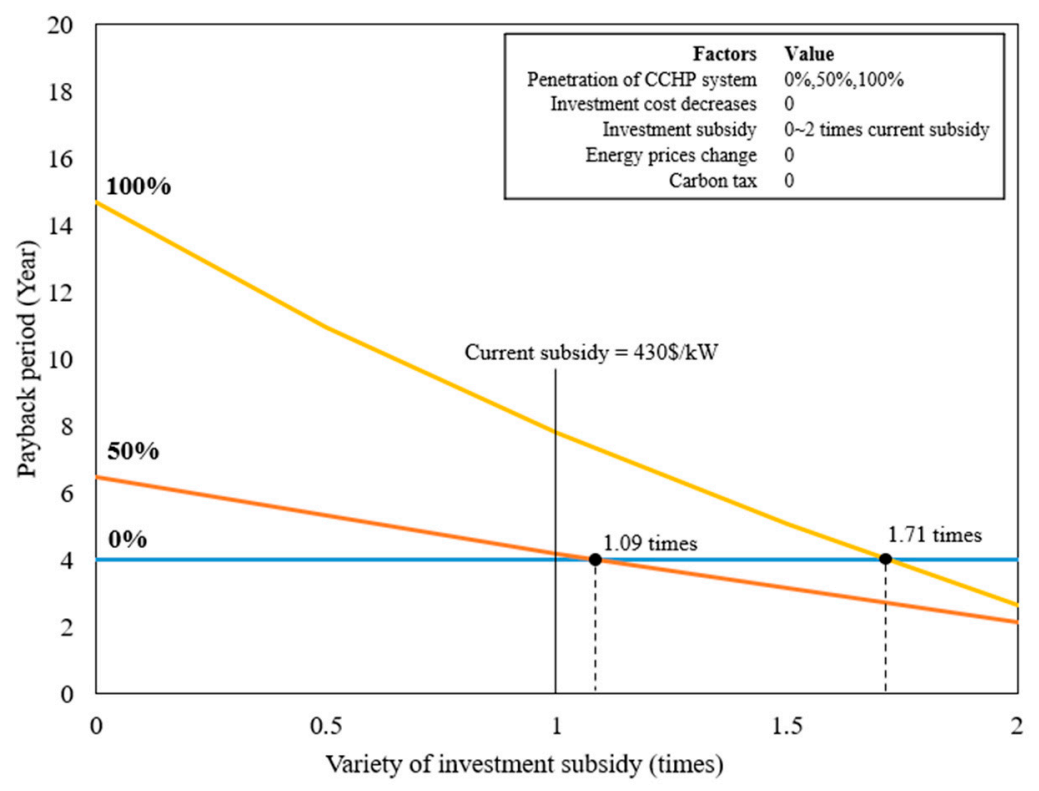

Figure 14. The impacts of the investment subsidy.

(4) Impact of a carbon tax on the economic performance of the CCHP system

The purpose of a carbon tax is to create economic value from defined environmental benefits such as the reduction of carbon dioxide emissions. Figure 15 shows the changes of the payback period in the three systems when the carbon tax is increased. The carbon tax has a positive effect on the economic performance of the CCHP system. With the increase of the carbon tax, the economy of the conventional system (without CCHP) decreases rapidly. When the carbon tax is more than $12.5 \$ /$ ton, it gives an economic advantage to the $50 \%$ CCHP system even without other incentive policies. The more the carbon tax increases, the environmental advantage is more prominent with the penetration of CCHP system. When the carbon tax reaches $25.5 \$ /$ ton, the economic performance of the $100 \%$ CCHP system is superior to that of the conventional system (without CCHP).

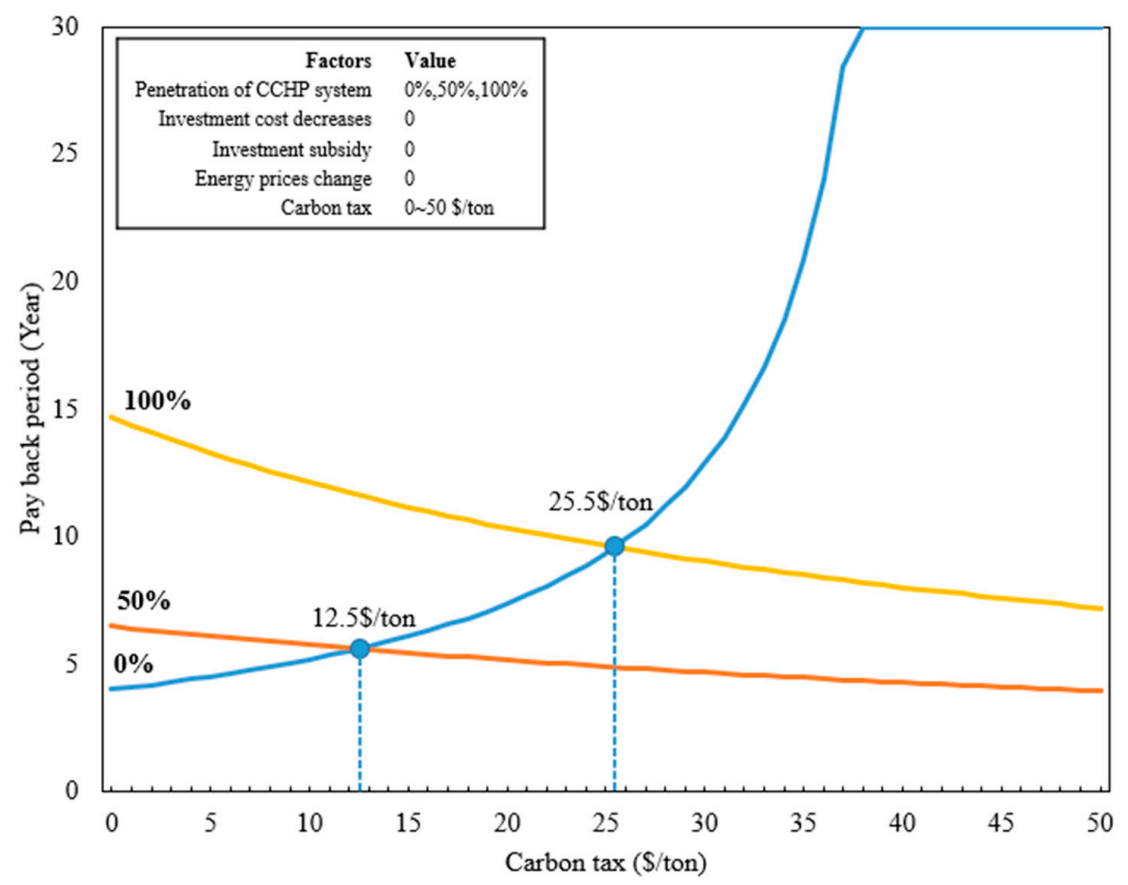

Figure 15. The impacts of the carbon tax. 


\subsection{Sensitivity Analysis}

In this section, an optimistic sensitivity analysis of the factors was conducted to obtain the effect of promoting the development of the CCHP system. The average degree of adjustment of natural gas and electricity price has been about $10 \%$ in the past [13], thus $10 \%$ was selected as the sensitivity index. Since the carbon tax has not yet been implemented, according to IEA's World Energy Outlook 2014 forecast, the carbon tax of China's power generation sector would be positioned at 10\$/ton in 2020 . Therefore, the carbon tax was analyzed with a sensitivity index of 10 . The analysis results are shown in Table 11.

Table 11. Sensitivity analysis of economic factors affecting the CCHP system.

\begin{tabular}{|c|c|c|c|c|}
\hline \multicolumn{2}{|c|}{ Factors } & Variety & Interval & Mean Sensitivity Value \\
\hline \multicolumn{2}{|c|}{ Investment cost } & Decrease $0-50 \%$ & $10 \%$ & 16.43 \\
\hline \multirow{2}{*}{ Energy price } & Electricity price & Increase 0-50\% & $10 \%$ & 27.60 \\
\hline & Natural gas price & Decrease $0-50 \%$ & $10 \%$ & 28.75 \\
\hline \multicolumn{2}{|c|}{ Investment subsidy } & Increase $0-50 \%$ & $10 \%$ & 7.45 \\
\hline \multicolumn{2}{|c|}{ Carbon tax } & Increase $10-50 \$ /$ ton & $10 \$ /$ ton & 14.89 \\
\hline
\end{tabular}

Table 11 shows that the adjustment of energy prices has the greatest impact on the economic performance of the CCHP system. From the results shown in Figure 12, the increase in electricity prices can give economic advantages to the CCHP system. However, the economic performance of the conventional system (without CCHP) also improves with the decrease in gas prices. Although the economic gap between the conventional system and the CCHP system is decreasing, it is still too large for promotion of the CCHP system. Therefore, an increase in electricity price will be beneficial to the promotion of the CCHP system. Compared with other factors, the carbon tax has less effect on the economics of the CCHP system, but the introduction of a carbon tax would lead to an increase in the environmental costs of conventional systems, which could improve the economic competitiveness of the CCHP system. The levy of the carbon tax can significantly promote the development of the CCHP system.

\section{Conclusions}

This study evaluated the economic and environmental performance of the CCHP system based on its dynamic payback period and carbon dioxide emissions and analyzed the impacts of different factors on the promotion of the CCHP system.

Taking a typical CCHP system of an amusement park resort in Shanghai, China, as a research case, the simulation of three CCHP systems with different penetrations was carried out. Based on the comparison of the different penetration, four factors (investment cost, energy prices, subsidies and a carbon tax) affecting the economic performance of the CCHP system were discussed and compared through a sensitivity analysis.

Some conclusions from the results and analyses above include:

1. As the penetration of the CCHP system increases, carbon dioxide emissions reduce, but the economic performance worsens because of the large investment cost.

2. The impacts of prices: The economic performance of the CCHP system with $50 \%$ penetration can be better than that of the conventional system if the investment cost is reduced by $48 \%$ or the electricity price is increased by $11.5 \%$. To promote the CCHP system with $100 \%$ penetration, investment costs must be reduced by $76 \%$ or electricity prices increased by $30 \%$.

3. The impacts of policies: The current investment cost and energy prices cannot be changed significantly in the short term. Therefore, incentive policies are an effective way to contribute to the economics of the CCHP system. The current subsidy can basically achieve promotion of the 
CCHP system with $50 \%$ penetration. With an increase of the penetration to $100 \%$, the subsidy should increase by 1.71 times. Furthermore, introduction of a carbon tax can highlight the superiority of the low-emission characteristics of the CCHP system. The CCHP systems with 50\% and $100 \%$ penetration will achieve economic competitiveness when the carbon tax reaches 12.5 and $25.5 \$ /$ ton, respectively.

4. According to the sensitivity analysis, electricity and gas prices have the greatest impacts on the economics of the CCHP system. However, changes in gas price cannot effectively reduce the economic gap between the CCHP system and conventional system. Although the impact of a carbon tax on the economics of the CCHP system is not the large, the environmental costs of the conventional system increase greatly with the development of carbon tax. Even if price concessions and subsidies were eliminated, the market competitiveness of the CCHP system would gradually increase. Therefore, it is necessary and significant to focus on the carbon tax for promoting the development of the CCHP system.

This paper takes the CCHP system in an amusement park resort in Shanghai as an example to analyze the influence of different factors on the promotion of the CCHP system. The results can provide guidance for improving the economics of the CCHP system. In the future, with the increase of the carbon tax, the CCHP system will become a better choice for investors.

There are fewer studies on the energy supply systems of amusement parks which have high energy consumption. This paper can provide a reference for amusement parks to establish a CCHP system to improve energy efficiency and reduce costs. However, the demand load and subsidies in different regions will be different. Therefore, the results will be different according to the specific research case. Nevertheless, the research method used in this paper has strong adaptability and practical application significance.

Author Contributions: Conceptualization, L.Z.; methodology, L.Z. and W.G.; software and validation, L.Z. and F.Q.; formal analysis, L.Z., investigation, L.Z. and Y.Y.; writing-original draft preparation, L.Z.; writing-review and editing, L.Z., W.G. and Y.Y.; and supervision, W.G. All authors have read and agreed to published version of the manuscript.

Funding: This research was funded and supported by the Key Technologies Research and Development Program, grant number 2018YFE0106100.

Conflicts of Interest: The authors declare no conflict of interest.

\section{References}

1. Wang, L.; Lu, J.; Wang, W.; Ding, J. Energy, environmental and economic evaluation of the CCHP systems for a remote island in south of China. Appl. Energy 2016, 183, 874-883. [CrossRef]

2. Papadimitriou, A.; Vassiliou, V.; Tataraki, K.; Giannini, E.; Maroulis, Z. Economic assessment of cogeneration systems in operation. Energies 2020, 13, 2206. [CrossRef]

3. Liu, M.; Shi, Y.; Fang, F. Combined cooling, heating and power systems: A survey. Renew. Sustain. Energy Rev. 2014, 35, 1-22. [CrossRef]

4. Xu, D.; Qu, M. Energy, environmental, and economic evaluation of a CCHP system for a data center based on operational data. Energy Build. 2013, 67, 176-186. [CrossRef]

5. Lin, H.; Yang, C.; Xu, X. A new optimization model of CCHP system based on genetic algorithm. Sustain. Cities Soc. 2020, 52. [CrossRef]

6. Li, L.; Yu, S.; Mu, H.; Li, H. Optimization and evaluation of CCHP systems considering incentive policies under different operation strategies. Energy 2018, 162, 825-840. [CrossRef]

7. Fragaki, A.; Andersen, A.N. Conditions for aggregation of CHP plants in the UK electricity market and exploration of plant size. Appl. Energy 2011, 88, 3930-3940. [CrossRef]

8. Pina, E.A.; Lozano, M.A.; Serra, L.M. Optimal operation and marginal costs in simple trigeneration systems including thermal energy storage. Energy 2017, 135, 788-798. [CrossRef] 
9. Tichi, S.G.; Ardehali, M.M.; Nazari, M.E. Examination of energy price policies in Iran for optimal configuration of CHP and CCHP systems based on particle swarm optimization algorithm. Energy Policy 2010, 38, 6240-6250. [CrossRef]

10. Dong, J.; Feng, T.T.; Sun, H.X.; Cai, H.X.; Li, R.; Yang, Y. Clean distributed generation in China: Policy options and international experience. Renew. Sustain. Energy Rev. 2016, 57, 753-764. [CrossRef]

11. Zheng, C.Y.; Wu, J.Y.; Zhai, X.Q.; Wang, R.Z. Impacts of feed-in tariff policies on design and performance of CCHP system in different climate zones. Appl. Energy 2016, 175, 168-179. [CrossRef]

12. Jradi, M.; Riffat, S. Tri-generation systems: Energy policies, prime movers, cooling technologies, configurations and operation strategies. Renew. Sustain. Energy Rev. 2014, 32, 396-415. [CrossRef]

13. Dong, R.; Xu, J. Impact of differentiated local subsidy policies on the development of distributed energy system. Energy Build. 2015, 101, 45-53. [CrossRef]

14. Wei, D.; Chen, A.; Sun, B.; Zhang, C. Multi-objective optimal operation and energy coupling analysis of combined cooling and heating system. Energy 2016, 98, 296-307. [CrossRef]

15. Cao, Y.; Wang, Q.; Wang, Z.; Jermsittiparsert, K.; Shafiee, M. A new optimized configuration for capacity and operation improvement of CCHP system based on developed owl search algorithm. Energy Rep. 2020, 6, 315-324. [CrossRef]

16. Gong, X.; Li, F.; Sun, B.; Liu, D. Collaborative optimization of multi-energy complementary combined cooling, heating, and power systems considering schedulable loads. Energies 2020, 13, 918. [CrossRef]

17. Yang, G.; Zhai, X.Q. Optimal design and performance analysis of solar hybrid CCHP system considering influence of building type and climate condition. Energy 2019, 174, 647-663. [CrossRef]

18. Tataraki, K.; Giannini, E.; Kavvadias, K.; Maroulis, Z. Cogeneration economics for greenhouses in Europe. Energies 2020, 13, 3373. [CrossRef]

19. Nami, H.; Anvari-Moghaddam, A.; Arabkoohsar, A. Thermodynamic, economic, and environmental analyses of a waste-fired trigeneration plant. Energies 2020, 13, 2476. [CrossRef]

20. Chu, X.; Yang, D.; Li, J. Sustainability assessment of combined cooling, heating, and power systems under carbon emission regulations. Sustainability 2019, 11, 5917. [CrossRef]

21. Wu, J.-Y.; Wang, J.-L.; Li, S. Multi-objective optimal operation strategy study of micro-CCHP system. Energy 2012, 48, 472-483. [CrossRef]

22. Mago, P.J.; Hueffed, A.K. Evaluation of a turbine driven CCHP system for large office buildings under different operating strategies. Energy Build. 2010, 42, 1628-1636. [CrossRef]

23. Tan, R.; Lin, B. The influence of carbon tax on the ecological efficiency of China's energy intensive industries-A inter-fuel and inter-factor substitution perspective. J. Environ. Manag. 2020, 261, 110252. [CrossRef]

24. Zhang, X.; Yang, L.; He, B.; Zhang, A.; Wang, F. Calculation method of auxiliary power consumption rate for combined heating cooling and power distributed energy system. Therm. Power Gener. 2017, 46, 88-92.

25. Abbasi, M.; Chahartaghi, M.; Hashemian, S.M. Energy, exergy, and economic evaluations of a CCHP system by using the internal combustion engines and gas turbine as prime movers. Energy Convers. Manag. 2018, 173, 359-374. [CrossRef]

26. Zhang, X.; Zeng, R.; Deng, Q.; Gu, X.; Liu, H.; He, Y.; Mu, K.; Liu, X.; Tian, H.; Li, H. Energy, exergy and economic analysis of biomass and geothermal energy based CCHP system integrated with compressed air energy storage (CAES). Energy Convers. Manag. 2019, 199, 111953. [CrossRef]

27. Zhu, X.; Zhan, X.; Liang, H.; Zheng, X.; Qiu, Y.; Lin, J.; Chen, J.; Meng, C.; Zhao, Y. The optimal design and operation strategy of renewable energy-CCHP coupled system applied in five building objects. Renew. Energy 2020, 146, 2700-2715. [CrossRef]

28. Li, Y.; Tian, R.; Wei, M.; Xu, F.; Zheng, S.; Song, P.; Yang, B. An improved operation strategy for CCHP system based on high-speed railways station case study. Energy Convers. Manag. 2020, 216, 112936. [CrossRef]

29. Feng, L.; Dai, X.; Mo, J.; Shi, L. Performance assessment of CCHP systems with different cooling supply modes and operation strategies. Energy Convers. Manag. 2019, 192, 188-201. [CrossRef]

30. Wang, J.-J.; Jing, Y.-Y.; Zhang, C.-F. Optimization of capacity and operation for CCHP system by genetic algorithm. Appl. Energy 2010, 87, 1325-1335. [CrossRef]

31. Lin, B.; Jia, Z. The energy, environmental and economic impacts of carbon tax rate and taxation industry: A CGE based study in China. Energy 2018, 159, 558-568. [CrossRef]

32. Ren, H.; Lu, Y.; Zhang, Y.; Chen, F.; Yang, X. Operation simulation and optimization of distributed energy system based on TRNSYS. Energy Procedia 2018, 152, 3-8. [CrossRef] 
33. Shrivastava, R.L.; Vinod, K.; Untawale, S.P. Modeling and simulation of solar water heater: A TRNSYS perspective. Renew. Sustain. Energy Rev. 2017, 67, 126-143. [CrossRef]

34. Calise, F.; d'Accadia, M.D.; Libertini, L.; Quiriti, E.; Vanoli, R.; Vicidomini, M. Optimal operating strategies of combined cooling, heating and power systems: A case study for an engine manufacturing facility. Energy Convers. Manag. 2017, 149, 1066-1084. [CrossRef]

35. Notice of Shanghai Municipal Price Bureau on Matters Concerning the Reduction of Industrial and Commercial Electricity Prices. Available online: http://www.sh.gov.cn/nw2/nw2314/nw2319/nw12344/ u26aw55678.html (accessed on 20 July 2020).

36. Khodaei, H.; Hajiali, M.; Darvishan, A.; Sepehr, M.; Ghadimi, N. Fuzzy-based heat and power hub models for cost-emission operation of an industrial consumer using compromise programming. Appl. Therm. Eng. 2018, 137, 395-405. [CrossRef]

37. China Banks Start to Lower Discounts on Mortgage Rates. Available online: https: //www.reuters.com/article/us-china-economy-mortgages/china-banks-start-to-lower-discounts-onmortgage-rates-paper-idUSKBN15O0AA (accessed on 20 July 2020).

38. Agency, I.E. World Energy Outlook 2014; OECD/IEA: Paris, France, 2014.

39. Commission SDaR. Special Support Measures for the Development of Natural Gas Distributed Energy Supply System and Gas Air Conditioners in Shanghai. Available online: http://http://www.shanghai.gov.cn/ Attach/Attaches/201703/201703061246348384.pdf (accessed on 20 July 2020).

(C) 2020 by the authors. Licensee MDPI, Basel, Switzerland. This article is an open access article distributed under the terms and conditions of the Creative Commons Attribution (CC BY) license (http://creativecommons.org/licenses/by/4.0/). 